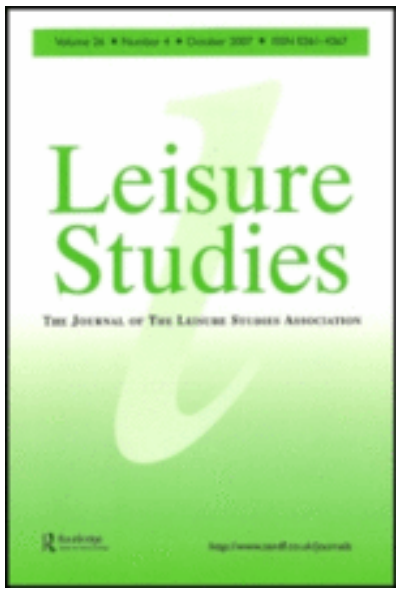

Knowing your place and commanding space: De/constructions of gendered embodiment in mixed-sex karate

\begin{tabular}{|r|l|}
\hline Journal: & Leisure Studies \\
\hline Manuscript ID & RLST-2019-0041.R2 \\
\hline Manuscript Type: & Original Paper \\
\hline Keywords: & gender, embodiment, space, combat sport, phenomenology \\
\hline \multicolumn{2}{|l}{} \\
\hline
\end{tabular}

SCHOLARONE $^{\text {TH }}$

Manuscripts 


\title{
Knowing your place and commanding space: De/constructions of gendered embodiment in mixed-sex karate
}

\author{
Feminists have long acknowledged that gendered divisions in access to spaces of \\ leisure, and how women and men physically take up that space, reproduces \\ gender inequality. This article will explore how karate practitioners participate in \\ the space of mixed-sex karate practice and how such uses of space de/construct \\ gendered embodiments and a gender hierarchy. Data presented is drawn from \\ nine months of ethnographic emersion within three karate clubs and fifteen \\ photo-elicitation interviews with karate participants from the three clubs. The \\ findings of this paper suggest that whilst women often occupied spaces of \\ expertise within the karate hall, gendered distinctions in uses of space emerged in \\ the more subtle ways in which women and men used their voice, responded to the \\ tacit and smelt dilemmas of sweat, and moved their bodies across physical space. \\ This research highlights both the potential of physical leisure practice to 'undo' \\ conventional gendered embodiments that particularly restrict women's \\ intentionality in the world (Young, 1980), and the power of spatially-attuned \\ research to illuminate the minute ways in which unequal gender relations are \\ naturalised, legitimised, and done.
}

Keywords: gender; embodiment; space; combat sport; phenomenology.

\section{Introduction}

As activities we predominantly choose to engage in, leisure practices play a significant role in the construction of our sense of identity (Aitchison, 2013) and our embodiment (Channon \& Jennings, 2014). Our embodiment is developed in relationship between the spatial dynamics of the places we occupy, our bodily senses, our feelings, intensions, and pre-existing sense of identity, and those we share spaces and places with (Pink, 2011). Differences in women and men's access to leisure spaces and spatial engagement within contribute to constructing gendered bodies that move through the world differently (Young, 1980). 
Karate is a sport and leisure practice that centres upon developing combative dispositions-techniques such as kicks, punches, strikes, and throws. Within karate women and men are given opportunities to use their bodies in ways which command space through the equally expected performance of karate techniques and training drills by women and men (Maclean, 2015). As such, how do women and men negotiate the unisex movements and tasks expected of karate practitioners, alongside gendered expectations of their bodies, in the mixed-sex shared space of karate?

By drawing on a combination of Young's (1980) phenomenological approach to gender and constructivist approaches to gender, this paper will explore how women and men marked and negotiated space within mixed sex karate practice, and how this impacted gendered embodiments and notions of a gendered hierarchy. Through exploring how karate practitioners move through physical space, assert their voice, and exude or cover up odours seeping from their bodies into the shared space of the karate hall, this paper will highlight the integral role of space to the de/construction of gendered embodiments and a gendered hierarchy. This research highlights the potential of physical leisure practices to nurture bodily dispositions that 'undo' conventional gendered embodiments that particularly restrict women's intentionality in the world (Young, 1980). In doing so, this paper contributes to literature on gendered embodiment, and embodiment in physical leisure practices.

\section{Gendered embodiment and space}

Our embodied being is subject to an intricate set of expectations of what it is to be a man or a woman that require intensive reflective bodily management (West \& Zimmerman,1987). This broaches not only our physical appearance, but also how we use or do not use our voice, how we smell, and how we visibly and tacitly move our bodies through, and interact with, the spaces we occupy. Underpinning gendered expectations of the body are expectations of distinction between women and men. Such 
differences are in turn drawn on to legitimise unequal power relations between women and men (Connell, 2009).

In adopting a phenomenological approach to understanding gender, Young (1980) highlights the centrality of lived experiences of women's bodies within the spaces and places they occupy in the construct of gendered ways of using, inhabiting, and perceiving the body. Women are suggested to form an embodiment that understands their bodies as objects within space orientating their body towards accommodating the needs and desires of others (Martin, 1998; Satina \& Hultgren, 2001) and forgoing their own intentions within the world (Young, 1980). Young (1980) suggests there are three modalities of feminine motility that are sourced in experiencing the body as an object: Ambiguous transcendence, inhibited intentionality, and discontinuous unity with surroundings. Ambiguous transcendence refers to restriction in movement through the world. This leads to inhibited intentionality whereby the possibilities of bodies in the $\underline{\text { world are restricted, which in turn, leads to a discontinuous unity between individuals' }}$ aims and their surroundings. These three modalities intertwine to construct a feminine bodily existence that's interaction with the world is restricted or immobilised, spatially confined, and has a severed link between the possibilities in the world and capacity within their bodies. As such, restricted use of space is central to a feminine embodiment.

In contrast, men are societally encouraged to experience their bodies as mechanisms to express themselves in the world, take up space, and where they can, to dominate (Connell, 1995; Martin, 1998; Pronger, 1999; Young, 1980). How these encouragements are embodied will vary across men and women based on factors including class, race, age, and the spheres they engage in. However, they present an 
overarching gendered framework that limits women's actions in the world and enable men's, recreating gendered access to power and status.

By combining both constructivist and phenomenological approaches to gender, we can see gendered embodiment as both responsive to ideologies of gender difference, and grounded in the lived experiences of such ideologies. As active agents in the construction of the spaces and relationships we are emplaced within, we may also build embodiments that challenge notions of difference between women and men, and thus 'undo' gender (Deutsch, 2007). As such, to understand gendered embodiment within leisure spaces, we must thus understand it's spatial components, and it's relation to ‘doing' or 'undoing' (Deutsch, 2007) gender.

\section{The gendered spatial division of leisure}

The gendered, spatial, division of leisure has long been highlighted and critiqued by feminist leisure researchers (For examples see: Aitchison, 2013; Mcrobbie \& Garber, 1975; Scraton \& Watson, 1998). The spatial separation of men and women within and across leisure institutions has been suggested to sustain a gender hierarchy by placing value in what men do, and reducing women's access to such socially valued knowledge and skills, whereby 'the more pronounced the degree of spatial gender segregation, the lower is women's status relative to men's' (Spain, 1993, p.137). Women and men's structured emplacement in predominantly separate leisure spheres thus contributes to the differing sets of everyday experiences, knowledge, and skill sets that develop different ways in which women and men come to use and experience their bodies (Young, 1980), re/create ideas of differences between women and men's bodies (Connell, 2009), and enable the legitimation of a gender order.

The sociology of leisure literature has long acknowledged sport as a prominently gendered space - as a male domain - sourced largely in the exclusion, side-lining, 
marginalisation, and/or segregation of women from men in sporting arenas (Burnstyn, 2004; Hargreaves, 1994; Mansfield, Cauldwell, Wheaton \&Watson, 2018). Not only is sport often marked as a male domain, Pronger (1999) suggests that spatial dominance within sports practice is used to perform male sexual dominance:

\footnotetext{
'Since, on their own, no penis and anus as mere body parts could ever produce the incessant territorial aspirations of their phallocentric master and society, a host of strategies and practices are promoted to encourage men and boys to take and enclose more space beyond the limited view of their "private parts" (Pronger, 1999, p. 381).
}

In this way sport acts as a mimetic field for performing patriarchal violation and dominance of another, whereby the invasion and control of space is positioned as central to sports practice, and sports practice to masculine embodiment.

Precisely because of sport's legacy as a male domain and disassociation with/discouragement of women, women's participation in sport is suggested to present challenges to a conventional feminine embodiment and women's uses of their bodies in space (Allen-Collinson, 2011). Allen-Collinson (2011) suggests sport is a particularly rich field for feminist phenomenological explorations of women's intercorporeal experiences of the body in motion. In engaging in sports practice, women are encouraged to spread their bodies across space to hit, slam, block, excellerate, jump, throw, intercept, and tackle, developing a relationship with their body that recognises the active capacity of their bodies (Kotarba \& Held, 2006; Pavladis \& Fullagar, 2016; Thorpe, 2009) and asserts their bodies across space. The extent to which sports women perform and develop dispositions that challenge conventional ideas of feminine embodiment and motility is dependent upon both the age at which such dispositions are learnt, and the gendered expectations of those who share the sporting space (Mennesson, 2012). 
However, the gendered spatial composition to best facilitate women's sports participation, whilst challenging the unequal power relations between women and men, is debated by sports feminists (Hargreaves, 1990). Whilst women-only sports practice can provide a safe space that enables women to challenge restrictions of conventional feminine embodiment (Brady, 2005; Mennesson, 2012), the sex-segregated structure of women's sports practice leaves room for the myths of men's biological, hierarchical difference to women to be reproduced (Hargreaves, 1990; McDonagh \& Pappano, 2008). As such, within separatist approaches to sport, power relations between men and women (outwith and within sport) remain unchallenged (Hargreaves, 1990). In turn, the meanings of women's embodied experiences of women-only sports practice is constructed in relation to a subordination to their male sporting counterparts.

A key hypothesis explored in sex-integrated sports research is whether or not sex-integrated sports practice challenges ideas of difference between women and men, and in turn, reduces inequalities between women and men (Channon, Dashper, Fletcher \& Lake, 2016). Whilst research suggests that sex-integrated sports practice can indeed challenge assumptions about the differences between women and men, and consequently support the formation of positive relationships (Anderson, 2008; Maclean, 2016), mixed-sex practice of sport has also been found to be spatially dominated by men. Men's spatial dominatance of mixed-sex sporting practice occurs through: taking the most prestigious playing positions (Henry \& Comeaux, 1999), hogging play (Comley, 2016; Hills \& Croston, 2011), and encroaching on spaces women occupy (Comley, 2016). Women in mixed-sex sport often subsequently create their own spaces for play or play subordinated aspects of the sport (Comley, 2016; Hills \& Croston, 2011). This draws further questions, as Hargreaves (1990) previously theorised, surrounding the capacity for toof sports that rely on masculinist frameworks of 
aggressive competition to undermine unequal power relations between women and men in sport whether practiced mixed-sex or not.

Negotiations of space and uses of the body in space within sex-integrated martial arts and combat sports (MACS) are done so whilst walking a particularly close line to a socially constructed ultimate resource of men's power and difference from women - fighting ability (McCaughey, 1997). Indeed MACS spaces have historically been constructed as male preserves (Matthews, 2016;Wacquant, 2004). Despite increasing numbers of women entering the field, boxing in particular has been suggested to remain marked as a male space where narratives connecting men to violence and power continue to be reproduced and consumed (Matthews, 2016). However, the practice of many martial arts delineates from a competitive framework found in boxing. As such, these mixed-sex sport spaces can perhaps escape the masculinist frameworks that Hargreaves (1990) suggests limits the gender transgressive capacities of mixed-sex sport.

Given the societal associations between masculinity and violence, this stream of sex-integrated research has had a particular focus on women's positions within MACS, and the moulding of women's uses of their bodies towards the conventionally masculine capacities of fighting (See: Maclean, 2015;2016; McCaughey,1997; Noel, 2009; Velija, Meirzwinski \& Fortune, 2013). Through the mastery of combative bodily dispositions women contend directly with men for their place in the sporting hierarchy (Maclean, 2015), and forge embodiments that reject notions of their body as fragile, passive, and vulnerable to men (McCaughey,1997; Velija et al., 2013).

Whilst the emerging literature on developments of bodily dispositions through combative practice brings attention to the carnal lived body (Sanchez Garcia \& Spencer, 2013; Wacquant, 2004) and the gendered lived body (Carlson, 2017; Channon \& 
Jennings, 2014; Noel,2009; Velija et al. 2013) the spatial nature of the gendered, carnal, lived body remains a relatively untouched mine of intricate detail that weaves together embodiment within physical activity contexts (Allen-Collinson, 2011). In this article I will demonstrate the centrality of uses of space to the de/construction of gendered embodiment within mixed-sex karate practice.

\section{Methodology}

To illuminate uses of space within karate, and the extent to which these embodied uses of space 'do' or 'undo' a gendered embodiment, the research adopted a sensory ethnographic design. A sensory ethnographic approach was chosen with the desire to explore the minute and mundane pieces of life-as-lived that build our embodied and gendered experiences of what is normal, grounded in an understanding of researcher and participants as "emplaced in social, sensory, and material contexts characterised by, and productive of, particular power configurations that they experience through their whole bodies and are constantly changing” (Pink, 2009:33).

In following a common trend of ethnographic fieldwork, data collection combined forms of participant observations and interviews from across three karate clubs situated in Scotland and the north of England: Lothian Wado-kai, Juniper karate club and Bushido. Whilst karate is commonly seen as a Japanese martial art, its practice emerged through a blend of Chinese, Japanese and Okinawan martial traditions that placed particular emphasis on slightly varying philosophies and physical practices (Tan, 2004). Reflecting it's bricolage past, contemporary karate clubs take various different forms with a prominent distinction being between those that are 'traditional karate' that position themself closely to the practice and philosophical origins of karate as a martial art, and those that are 'sports karate' that utilizes the techniques of karate for competition. The type of karate practiced impacts the cultural constructions of 
appropriate interactions within the dojo, and as such, the forms of gendered embodiment de/constructed. The three clubs within this study blended both 'traditional' and semi-contact 'sport' karate whereby classes entailed both traditional techniquebased drills, and competition specific training drills. Participants within these clubs were aged between 16-74 with the majority of participants aged between 16-20 and then 30-45. Skill levels ranged from absolute beginners to members whom had over 30years experience and competitive accolades. My position as an established karate practitioner eased entry and participation in the clubs where participant observations were carried out over the course of nine months.

The participant observations took the form of a sensorially attuned 'observant participation' (Wacquant, 2004) that sought to reflect on the sensory processes my body underwent during training in order to make the normal and taken-for-granted pieces of my embodiment visible and open to gendered critique. As many of our sensory experiences are taken-for-granted and overlooked in our reflections of our experiences, each karate class I sought to focus on one sense in order to encourage a reflection that may tap into overlooked ways in which we use a sense, the meanings such sensory expressions hold, and their impact on gendered interactions and embodiments. The senses focused on largely reflected the 'western five' - sound, smell, taste, touch, and sight - but also included feelings of movement and heat. Whilst there are indeed many other senses that have been identified and could have been explored (Pink, 2009), these senses were selected as they were the sensations most frequently recognized and discussed within karate classes. Sensory observations were described in field notes after each karate class, generating a depth of data on each sense.

Fifteen individual photo-elicitation interviews ( 6 men, 9 women) supplemented my own embodied experiences of karate practice with insights into the embodied 
experiences of others. Participants were asked to take photos to show 'the good, the bad, and the ugly of karate' in an attempt to draw a broad picture of their experiences within the sport. Interviews were structured around the participant's stories of their photographs, enabling the meanings and experiences central to the participants embodied experience of karate to lead the conversation (Wang, 1999). I interspersed these discussions with questions interrogating gendered elements and sensory experiences related to their photographs and stories. In turn, this enabled a more complex multi-layered approach to understanding the doing and undoing gender. From these discussions, gendered distinctions in the ways in which participants talked of experiencing and using space with their bodies in the karate hall emerged. Interview transcripts, photographs, and field notes were then thematically coded for sensory codes emerging most prominently as informing karateka's embodied experiences and sense of embodiment. These were smell, tacit engagement, voice/sound, and movement in space. The findings of this article present the interplay of sensory experiences in de/constructing a gendered embodiment, and gendered spatial patterns emerging in sensory uses of the body within karate, that in turn illuminate the multi-layered complexities of gendered embodiment.

\section{Findings and Discussion}

\section{Occupying Space Through Physical Movement}

Interactions within karate are structured around a very visible hierarchy of status reflected in the varying coloured belts practitioners wear that mark their graded level of ability (Maclean, 2015). This structure ascribes the level of respect that should be granted to a practitioner, suitable interactions between practitioners, and physically structures and divides the space of the hall, lining practitioners from lowest grade to 
highest grade. Despite this strict hierarchal structure of practice that denoted uses of space within the karate hall, gendered distinctions in the ways in which men and women occupied physical space emerged. The extent to which gendered distinctions emerged varied between those women and men who had started karate as children, and those who had started karate as adults.

There was a tendency for women, particularly those who started karate in adulthood rather than as a child, to position themselves beside the lower grades when standing lined up, or to avoid partnering with higher grades, despite recognising the benefits of training with high grades:
When I was a low grade I used to want to train with people that were higher grades and black belts because I used to think: you always want to be pushed, and you want to be with people who are like that. But part of me feels a bit guilty if I am training with someone who is better than me. I think they're not getting anything out of it. Sandra, Bushido.

Training with higher grades and positioning themselves beside higher grades was seen as occupying a privileged space. In avoiding doing so, and rather positioning themselves beside lower grades, women avoided situating themselves in prestigious positions that reflect the competency of their karate abilities. By consistently spatially aligning themselves with lower grades, some women expressed a subordinate understanding of their bodily abilities and themselves. Many women also found ways to minimise the space they used by moving out the way for others, moving into smaller spaces for their own practice so others had room, or hiding outwith of the gaze and space requirements of others:

I like being at the end next to the lower belts, hiding in the corner. I mean the other week I was right at the back behind the pillar and I loved it! I felt I was in me own little space doing me own thing. Rebecca, Bushido. 
Such actions not only refrained from using the body to take up space, it also limited women's abilities to progress by limiting the uses of their body in karate practice and not gaining the experience of training with higher grades.

Men who started the sport as adults did not appear to hide themselves, frequently position themselves at the bottom of their graded group, nor frequently give up their training space needed for training to others. For some men who started karate in adulthood, the problem was the opposite - they used up too much space:

James and Peter were having an intense sparring match, so intense they took up most of the room. They moved from one side to the other, bumping and barging past others - including senior grades - fixed on their sparring. After moving straight through Stuart and Steph's sparring, Stuart, a black belt, confronted them: 'Ay, watch what you're doing lads.' Field note, Juniper karate club.

Indeed many men who started karate as adults were more forthcoming than their female counter parts to move throughout the hall for their own practice and seek to spar or train with higher grades, sometimes, as in the field note above, crossing lines of hierarchical respect when doing so. Although their movements were sometimes drawn in by more senior graded men or by the instructor through verbal instructions to 'calm it down' or 'watch where you're going', women rarely confronted men who crossed into their training space.

These men's bodily movements demonstrated a comfort with taking up space in the karate hall, an obliviousness to their use of space being problematic, and in some instances, an air of entitlement to such space. Their use of space not only asserted an alignment with prestigious spaces in the hall often above their rank, it also marked an entitlement to women's space (Comely, 2015). This reoccurring gendered pattern of uses of space in the hall affects both the experience and subsequent meanings women and men attached to their own bodies (Satina \& Hultgren, 2001), leading the former to 
an accommodating and self-subordinating embodiment, and the latter to an embodiment that was freely moving and deserving of expression in space.

However, amongst the adults who had started karate as children, uses of their bodies across space in the karate hall were more similar than different. Both women and men would confidently take their place in the hall, with women commonly positioning themselves at the highest point of the graded line above men of the same grade within two of the clubs I trained with. These women and men would cover the hall as they sparred weaving amongst the other practitioners, at times nudging others out the way to maintain their space, take to the floor to demonstrate movements and kata to the rest of the class, and confidently extend their body's limbs, and swiftly move across others trajectories to perform well. The marked focus and confidence of women who started karate as children in commanding their bodies through shared space in comparison to women who started karate as adults points towards the pervasiveness of early conditioning of our bodies (Martin, 1998; Mennesson, 2012) and the potential of physical cultures in forming our gendered embodiments. As such, karate practice offered women a bodily conditioning that deviated from a conventional, spatially restrictive, feminine embodiment (Young, 1980) through broaching a recognition of their bodies as skilled, often more skilled than men, and thus worthy of occupying space.

An exception to the gender neutralised occupancy of space amongst those who had practiced karate since childhood appeared when their bodies were exposed:

At the end of the class I continued to chat to Steven as we packed our hand and feet protectors into our bags ready to leave. As we were chatting Steven started to take his karate top and trousers off to change into jeans and a t-shirt. I anxiously focused on maintaining eye contact with him as he continued to talk so casually and comfortably standing only in his boxers. As I left the hall a dozen men and boys remained in the now 
spacious hall changing and chatting about the class. I squeezed into the cramped women's toilet where the girls and women got changed. Field note, Lothian Wado-Kai Men's freedom in contrast to women's to undress within the hall and expose their bodies worked to construct the karate hall as a space for men, framed by a heteronormative male gaze. Within this process women's bodies were marked as 'other', as sexual, and as such, bodies that cannot be shown. This in turn marks the karate hall as a form of male preserve (Matthews, 2016) despite the many challenges women's karate excellence and childhood participation poses to gendered power relations (Maclean, 2015).

Those who started karate as adults and those adults who started when they were children share the same karate hall, and as such, both sets of gendered or de-gendered uses of space meet in the hall, and come to negotiate the space. Taken together, despite formal spatial divisions of the hall dictated by level of ability, the overall pattern points towards men's comfort with their bodies and use of their bodies within the karate hall, whilst women tread precariously along lines of hiding their (sexualised) body, limiting its active occupation of space, whilst fulfilling the physical, expressive, requirements of karate practice.

\section{Sweaty smells and sweaty bodies}

Karate practitioner's use of space is not confined only to the floor space in the hall that they stand in and move their bodies through to practice their art. The command of their voice, and exuding smell, are ways in which karate practitioners mark space and take up space within the karate hall. The physical exertions of the body moving through space make sport an arena where sweat, and the smell of sweat, is an inevitable component of the sporting body (Hockey \& Allen-Collinson, 2007). A particularly problematic area for karate practitioners were their hand and feet protectors which appeared resistant to 
washing away the smell of stale sweat. As practitioners punched and kicked their way across the hall, a trail of smell followed from their protectors. The merging smells of sweaty bodies, karate suits, and equipment was something karate practitioners had to become accustomed to when training, and their own propensity to sweat was something they had to come to terms with:

The karate hall is a pretty smelly place. You get used to it to the point you don't even notice it. I think if you do sport you expect to smell a bit. If you didn't, you'd be worried you hadn't been doing it (training) right! Katie, Bushido.

Being a karate practitioner entailed accepting and normalising an olfactory condition that one will mark their place across the hall with the smells of physical exertion, and that one will need to get used to others smells of exertion.

Whilst a normal and inevitable part of sports practice, smell is also embedded with gendered and moral expectations that mark sweat as a scent particularly undesirable for women (Classen, 1998; Waitt, 2014) and that contradicts expectations of feminine embodiment to be orientated towards the desires of others (Young, 1980). Women often view an orientation to the-body-as-seen, and as such spatially removed or distant, as a solution to the tactile and olfactory threat of sweat in action (Waitt, 2014). Yet, rather than avoiding the exertion of karate classes to avoid exuding sweaty bodily smells, some women managed the scent demands of femininity by wearing perfume or deodorant on top of a freshly washed suit. Instead of lingering a smell of sweat as they moved across the hall, these women infused their movements with feminine fragrances. Through such actions these women's presence within the karate hall was marked, and marked in gender distinct way.

For many women, the renegotiation of sweaty smells as a symbol of hard work undermined the common gendered and moral frameworks around smell, transforming it into an accepted, and expected element of being a karate practitioner: 
I came out of Paul's class absolutely soaked. The sweat was literally dripping off me, my face was beetroot, and I was stinkin' (of sweat), but that's what you want. You want to come out like that, it shows that you've really worked and you've had a great class. Steph, Juniper karate club.

Through this transformation, women karateka were able to justify their imprint in the smellscape of karate classes based on notions of working hard and being a good karateka. Such a framing of smell as hard work has more commonly been found to normalise and value men's exertions of sweat, and in turn legitimise gender hierarchies (Waitt \& Stanes, 2015). In marking their space and movement through the karate hall through the scents of either bodily sweat, perfume, or both, women asserted their bodily being in the karate hall, and in doing so, marked their bodies as worthy of taking up space, working hard and being valued (Satina \& Hultgren, 2001).

Sweat not only took up space and asserted place within the karate hall through smell, but also through tacit exchanges between bodies. Karate practitioners were often tasked to bridge personal spatial boundaries that involved the rubbing together of bodily fluids:

As I kicked towards Mathew's face I could see a splash of sweat spray from my footpad towards his face, and even worse I could see Mathew's eyes close and face screw just for a second before he opened his eyes again as if to pretend nothing had happened - nothing disgusting had happened. I felt embarrassed, but continued to kick. To ease my embarrassment I reminded myself that I had experienced the sweat of others splash onto my face or be squashed onto my body in a close encounter many times before, and that the disgust it brings only exists momentarily. Field notes, Lothian Wado-kai.

Within such instances, practitioners are given privileged access to the intimate space of another, whereby sweaty smell and sweaty touches become a normal part of women and men's embodiment within the karate hall. Here, it appeared the 
interpretation of sweaty bodies as hardworking karate bodies enabled women and men practitioners to transcend taboos of smell, and expectations of femininity, to mark their space within the hall through smell in rather similar ways.

\section{'Kiai!': Making women's voices heard}

Shouting is another fundamental way in which practitioners command space within the karate hall. Whether it is the instructor shouting instructions to the class, practitioners shouting to add emphasis and aggression to their techniques, or practitioners cheering for class mates during fitness drills or mock competitions, the use of voice is frequent and centrally important to karate practice. The prominent type of shouting engaged in by karate practitioners is the 'kiai' - a shout placed on the exertion of a technique deemed to finish an opponent. The kiai is a short and sharp shout teamed with a facial aggression that contributes to the set of bodily dispositions expected of karate practitioners. This style of using voice not only embodies an ethos of control and aggression, it also works to assert confidence in combative techniques and power position within the karate hall:

I say to some of the lower grades who maybe aren't as confident yet, I tell them its important to kiai. To prove the point, in the middle of training, I'll give out a big kiai and say to them 'did anyone flinch?' And the answer is no ... It's not just standing in the class shouting, it's a release, its part of the technique... They just need to realise that no one cares; it just shows you've done the move and you know what you're doing. Stuart, Juniper karate club.

I think if you have someone beside you who is loud and powerful, and you're quiet, I think you feel more like you're in the background. So I tried to make it a bit louder. Even though I'm not the greatest person at karate I think if I am good at kiai-ing at least that's something. Kirsty, Bushido. 
Whilst these vocal expressions are expected of both women and men, gendered reactions to vocal expressions in sport have been noted in tennis, whereby the media alongside sports governing bodies have been highlighted as policing women's grunting, but not men's (Kennedy, 2001). Conducting assertive, loud uses of voice that commanded the hall and boomed ones determination in combat appeared troubling for some women - much more noticeably than women's discomforts utilising physical space through movement. When lined up, performing solo, or sparring, some women would remain completely quiet, or perform quiet kiais with uncertain voices. Explanations from instructors were often given to try and convince quiet women of the essential use of their voice to perform karate properly. Two of the clubs used specific training drills to tackle women's reluctance to kiai: grouping the women to perform moves with loud kiais whilst the men were allowed a rest and only allowing the women to join the men one by one as they kiaied appropriately; or asking the women to perform the same movements repetitively, often in front of the whole class, until their kiai met the volume and assertive standards of the instructor. In contrast to the treatment of women's grunting in tennis, the actions of karate instructors encouraged women to display a loud, aggressive, confidence when throwing their karate techniques.

The longer women had participated in karate the more comfortable they appeared kiai-ing in the karate hall, with senior graded women appearing unfazed as they kiaied aggressively and freely. Kirsty, an intermediate karate practitioner reflects on the normalization process of kia-ing:

When mums start (karate) they look mortified when you tell them they need to shout in front of everyone. And to be fair, I thought it was strange when I first came here too. I thought 'I'll get this wrong and look an ejjit infront of everyone'. But, Sensei Katie insists we must kia! So, you get used to it - I love it now. You can't shut me up! Kirsty, Bushido. 
The embodied comfort to kiai thus appears as an outcome of ongoing direct pedagogic action from karate instructors (Channon, 2018). When women did kiai, they did so with a notably higher pitch than men. In doing so, women found a way to manage both presenting femininity whilst engaging in an aggressive use of voice and face more commonly associated with men, but crucial to the sports practice. For many women, kiai-ing was seen as an important part of embracing a fighting spirit, and was experienced as an empowering expression of their karate identity:

I love kiai-ing. You feel a buzz, a strength, right through your body. It makes you feel strong, like you've channeled all this energy through into your punch. In that second you just feel completely like a karate athlete from head to toe. Steph, Juniper karate club.

Through developing the skills and confidence over time to vocally assert themself and their intentions within the karate hall, karate practice encouraged women to undo passive embodiments, and develop an active and assertive embodiment - thus undoing gender (Deutsch, 2007). This remolded embodiment was associated with benefits that reached beyond the karate hall:

I was proud of me self at work yesterday because there was an incident with my manager and I didn't like the way he spoke to me and I dealt with it - I actually dealt with it and told him. I felt dead proud of me self for that because I probably wouldn't of done that before (I started karate). You know, you have to assert yourself in karate, even if it's just announcing the name of a kata, and I hate doing it! But I thought possibly the confidence from doing it in karate is maybe... you know... changing these other things in me life. Rebecca, Bushido.

The use of karate practitioners voice to assert aggression and dominance in their practice was a disposition more quickly embodied by men. In doing so, they make a vocal claim that marks dominance in the hall: 
I have got no problem with Kiai-ing. If I'm going to do something I'm going to let everyone hear about it. I've won more points by missing and kiai-ing than not. Even when I've known its missed in competition, I'd still give it the big kiai and look as if I believed I'd scored, and then referees think - I didn't see it but it must of been in! Stuart, Juniper karate

It was notable that the men's kiais were louder than the women's. Two men in particular kiaied noticeably louder and longer than the rest. This was strange as a punch is sharp and so a kiai also expected to be sharp. The kiais of these men sounded like a warrior shouting along their run-up into battle. A group of teenage girls in the class giggled at this. Field notes, Lothian Wado-kai.

In Stuart's case, his kiai was successful in convincing others of his dominance over his opponents, despite the physical reality being different. For the men in my field notes, the reception of their claim to dominance was quite different. Although the girls' laughter may partly be in relation to insecurities they may have held themselves around kiai-ing, in this instance, the laughter appeared to be directed towards the men's assertions to dominance. The men's display of dominance evidently did not convince the girls, who asserted confidence in their own judgments and positions as karate practitioners by laughing. Here, the hierarchical structure of karate based on the belt system creates a space whereby girls can laugh at men asserting their dominance without risk.

Instructors too used their voices' volume and tone to set out their authority. Although the instructors I trained under came from differing clubs, there were similarities across the manner in which they exerted their voice: Calm and smooth when giving instruction; loud and faster paced when they wanted their student to increase the pace and intensity of their practice; and assertive and sure when instructing students to change or adapt movements of the body to reach the correct technical standard. 
Already holding an ultimate position of power, what instructors said to their students, and how they said it, held particular power in shaping the confidence of their practitioners to express and explore their bodies' abilities within the space of the karate hall:

\begin{abstract}
He noticed that I couldn't do the combination and singled me out. I understand that he is there to help and correct, but he wasn't. He made me do the move on my own but didn't come and stand next to me, he spoke in a loud voice so that the rest of the class and spectators could clearly hear that I couldn't do it. I felt as if he was laughing at me - he even smirked at one point - and making it his business to intimidate me... It was the manner in which he spoke to me that upset me. I was trying my best but got flustered as he was singling me out. He spoke in a loud voice, 'that's not sliding, that's stepping!' I felt if he had come over to me and had a quiet word and shown me what to do I would have understood more and reacted better to him. This went for a few minutes and then I could feel myself getting angry. I glowered and at him... I felt like crying. He made me feel totally incompetent and very small. Rebecca, Bushido
\end{abstract}

Whilst this use of voice to embarrass and belittle a student was not routine of karate instructors, the deeply hierarchical structures of power within karate enabled this vocal assertion of power and disempowerment to occur. The vastly disproportionate quantity of men in comparison to women occupying roles as instructors meant that this form of disempowerment was notably committed by men. In this incident, this worked to backtrack Rebecca's belief in her body as an active and capable body, and her worth in using her body to command space in the karate hall, reinforcing an inhibited intentionality (Young, 1980).

\title{
Conclusion
}

What it is to be a woman or be a man is constructed in our everyday lived and emplaced corporeal interactions. Ideas of gender that mark power differentials between women 
and men do not exist purely in the structures of society, but are spatially located on bodies, and are negotiated through situated bodily performances of difference. The leisure spaces we can participate in and the way in which we use our bodies in those spaces are as such key parts in the construction of our gendered embodiment that in turn maintain social inequalities between women and men.

Constructions of gendered embodiments in mixed-sex karate practice entail a tension between two spatial hierarchies: of grade and gender. Karate's sex-integrated structure and uniform set of bodily demands constructs karate as a place with potential to develop women and men's bodily uses and movements in manners which 'undo' gendered difference and form a unisex 'karate embodiment'. Further it provides a setting where women can be recognised to outperform men at a karate embodiment (Maclean, 2015), and as such, access more, and more prestigious, spaces than men. Karate embodiment thus offered an alternative embodiment to the spatial restriction entailed in a conventional feminine embodiment (Young, 1980), structured by the bodily and spatial rules of karate's graded, rather than gendered, hierarchy of status (Maclean, 2015).

Whilst on the surface men and women karate practitioners performed the same techniques and training drills as one another, the sensory ways in which they utilised space to do so revealed nuanced ways in which imprints of gender permeated practitioners bodily motions in the karate hall. Through bodily expressions, such as the volume and pitch of a kiai, or the way one commanded space through movement, or hid into a small space for practice, some women and men's practice of the unisex bodily movements of karate were infused with gendered markings. Men's comfort with using their bodies within the karate hall enabled them to territorialise space in the hall (Pronger, 1999) to fully perform their practice. Through positioning themselves with 
lower grades, in smaller spaces, and with quiet or silent vocal assertions drowned out amongst the noise of the karate hall, some karate women embodied a subordinate understanding of their bodily abilities and themselves. Such gendered divisions of space mirror those found within the mixed-sex sport literature (Comley, 2016; Henry \& Comeaux, 1999; Hills \& Croston, 2011). These spatial inequalities created a gendered hierarchy prioritising men's spatial needs, that in turn enabled men to perform karate requirements more fully and freely than women, and ultimately assert men's power within the arena.

An overall pattern of men's dominance in karate spaces may reflect the closeness with which the spatially commanding embodiment of karate sits to a masculine embodiment men are likely to have experienced and developed in other areas of their lives (Connell, 2009; Martin, 1998) and the distance with which such an embodiment sits from feminine embodiment (Young, 1980). As such, the gendered distinction in uses of space does not necessarily mean that changes to women's embodiment were not occurring in ways that undo gender. Indeed many women pointed towards increased spatial uses of their body in karate, and the capacity of such an embodiment to transgress into other areas of their lives. Such transitions in bodily intentionality were sometimes a product of deliberate pedagogic work by instructors (Channon, 2018) and other times an unintentional outcome of karate practice. Karate practice thus enabled women to reframe their relationship with their body as one grounded in a physical agency, capacity, and worth to address their subjective goals in the world. The longer women practiced karate, the more this appeared to contribute to an undoing (Deutsch, 2007) of the spatially restrictive elements of feminine embodiment. 
The propensity for differences in commanding space in the hall to be expressed by those who started karate as adults in comparison to those who started karate as children suggests that ways of using our bodies are much easier learnt than unlearnt. This suggests that rather than an 'undoing' of a gendered embodiment, mixed-sex karate practice from a young age develops a counter embodiment that develops alongside, or instead of, the spatially confined feminine motility outlined by Young (1980). As such, karate's sex-integrated structure and non-competition orientated hierarchy of ability presents potential for creating relationships of equality between women and men sought by Hargreaves (1990) when the practice begins in childhood. Further research exploring how women and men's embodied spatial relations within the karate hall reflect or relate to their embodied relations in other settings would meaningful add to understandings of de/constructions of gendered embodiments in sport. 


\section{References}

Aitchison, C. (2013). Gender and leisure: Social and cultural perspectives. London: Routledge.

Allen-Collinson, J. (2011). Feminist phenomenology and the woman in the running body. Sport, ethics and philosophy, 5(3), 297-313.

Anderson, E. (2008). 'I used to think women were weak': Orthodox masculinity, gender segregation, and sport. Sociological Forum, 23(2), 257-280.

Brady, M. (2005). Creating safe spaces and building social assets for young women in the developing world: A new role for sports. Women's Studies Quarterly, 33(1/2), 35-49.

Burstyn, V. (1999). The Rites of Men: Manhood, politics, and the culture of Sport. Toronto: University of Toronto Press.

Carlsson, H. (2017). Researching boxing bodies in Scotland: Using apprenticeship to study the embodied construction of gender in hyper masculine space. Gender, Place \& Culture, 24(7), 939-953.

Channon, A. (2018) Martial arts studies and the sociology of gender: Theory, research and pedagogical application. In P. Bowman (Ed.) The Martial Arts Studies Reader (pp.155-170). London: Rowman and Littlefield International.

Channon, A., Dashper, K., Fletcher, T., \& Lake, R. (2016). The promises and pitfalls of sex integration in sport and physical culture. Sport in Society, 19(8-9), 1111-1124.

Channon, A., \& Jennings, G. (2014). Exploring embodiment through martial arts and combat sports: A review of empirical research. Sport in Society, 17(6), 773-789.

Classen, C. (1998). The scented womb and the seminal eye: Embodying gender codes through the senses. In Classen, C. The Colour of Angels: Cosmology, gender and the aesthetic imagination (pp. 63-85). London: Routledge.

Comley, C. (2016). 'We have to establish our territory': How women surfers 'carve out' gendered spaces within surfing. Sport in society, 19(8-9), 1289-1298.

Connell, R. (2009). Gender. Cambridge: Polity Press

Connell, R. (1995). Masculinities. Cambridge, Polity Press

Deutsch, F. (2007). Undoing Gender. Gender and Society 21(1): 106-127.

Hargreaves, J. A. (1990). Gender on the sports agenda. International Review for the Sociology of Sport, 25(4), 287-307. 
Hargreaves, J. (1994) Sporting Females: Critical issues in the history and sociology of women's sports. London: Routledge.

Henry, J.M., \& Comeaux, H.P. (1999). Gender egalitarianism in coed sport: A case study of American soccer. International Review for the Sociology of Sport, 34(3), 277-290.

Hills, L.A., \& Croston, A. (2011). 'It should be better together': Exploring strategies for 'undoing' gender in coeducational physical education. Sport, Education and Society, 17(5), 591605.

Hockey, J. \& Allen-Collinson, J. (2007). Grasping the Phenomenology of Sporting Bodies. International Review for the Sociology of Sport, 42(2), 115-131.

Kennedy, E. (2001). She wants to be a sledgehammer? Tennis femininities on British television. Journal of Sport and Social Issues, 25(1), 56-72.

Kotarba, J., \& Held, M. (2006). Professional Female Football Players: Tackling Like a Girl? In Waskul, D \& Vannini, P (eds.) Body/Embodiment: Symbolic interaction and sociology of the body (pp.153-16). Aldershot: Ashgate.

Maclean, C. (2015). Beautifully Violent: The Gender Dynamic of Scottish Karate. In Channon, A., \& Matthews, C. (eds.) Global Perspectives on Women in Combat Sports: Women Warriors around the World (pp.155-171). London: Routledge.

Maclean, C. (2016). Friendships worth fighting for: bonds between women and men karate practitioners as sites for deconstructing gender inequality. Sport in Society, 19(8-9), 1374-1384.

Mansfield, L., Caudwell, J., Wheaton, B., \& Watson, B. (Eds.). (2018). The Palgrave Handbook of Feminism and Sport, Leisure and Physical Education. Palgrave Macmillan UK.

Martin, K. (1998). Becoming a gendered body: practices of preschools. American Sociological Review, 63(4), 494-511.

Matthews, C. R. (2016). The tyranny of the male preserve. Gender \& Society, 30(2), 312-333.

McCaughey, M. (1997). Real Knockouts: The physical feminism of women's self-defense.

London: New York University Press.

McDonagh, E., \& Pappano, L. (2008). Playing with the boys: Why separate is not equal in sports. New York: Oxford University Press.

McRobbie, A., \& Garber, J. (1975). Girls and subcultures: an exploration. In Hall, S \& Jefferson, T (eds.) Resistance through rituals: Youth subcultures in Post-war Britain (pp 209229). London: Hutchinson.

Mennesson, C. (2012). Gender regimes and habitus: An avenue for analyzing gender building in sports contexts. Sociology of Sport Journal, 29, 4-21.

Noel, H. (2009). Un-doing gendered power relations through martial arts?. International Journal of Social Inquiry, 2(2), 17-37.

Pavlidis, A., \& Fullagar, S. (2016). Sport, gender and power: The rise of roller derby. London: Routledge.

Pink, S. (2009) Doing Sensory Ethnography. London: Routledge

Pink, S. (2011). From embodiment to emplacement: re-thinking competing bodies, senses and spatialities. Sport, Education and Society. 16(3). pp343-355.

Pronger, B. (1999). Outta my endzone: Sport and the territorial anus. Journal of sport \& social issues, 23(4), 373-389.

Sanchez García, R. \& Spencer, D. (Eds.) (2013). Fighting scholars: Habitus and ethnographies of martial arts and combat sports. London: Anthem Press. 
Satina, B., \& Hultgren, F. (2001). The absent body of girls made visible: embodiment as the focus in education. Studies in philosophy and education, 20, 521-534.

Scraton, S., \& Watson, B. (1998). Gendered cities: Women and public leisure space in the 'postmodern city'. Leisure studies, 17(2), 123-137.

Spain, D. (1993). Gendered spaces and women's status. Sociological theory, 11(2), 137-151.

Tan, K. (2004). Constructing a Martial Tradition: Rethinking a Popular History of Karate-Dou. Journal of Sport and Social Issues, 28, 169- 192.

Thorpe, H. (2009). Bourdieu, feminism and female physical culture: Gender reflexivity and the habitus-field complex. Sociology of Sport Journal, 26(4), 491-516.

Velija, P., Mierzwinski, M., \& Fortune, L. (2013). 'It made me feel powerful': women's gendered embodiment and physical empowerment in the martial arts, Leisure Studies, 32(5), 524-541.

Wacquant, L. (2004). Body and Soul: Notebooks of an Apprentice Boxer. Oxford: Oxford University Press.

Waitt, G. (2014). Bodies that sweat: the affective responses of young women in Wollongong, New South Wales, Australia. Gender, Place \& Culture, 21(6), 666-682.

Waitt, G., \& Stanes, E. (2015). Sweating bodies: Men, masculinities, affect, emotion. Geoforum, 59, 30-38.

Wang, C. (1999). Photovoice: A participatory Action Research Strategy Applied to Women's health. Journal of women's health, 8(2), 185-192.

West, C., \& Zimmerman, D. (1987). Doing Gender. Gender and Society, 1(2), 125-51.

Young, I. (1980) Throwing like a girl: A phenomenology of feminine body comportment, motility, and spatiality. Human Studies, 3(2), 137-156. 